\title{
Thickness difference induced pore structure variations in cellulosic separators for lithium-ion batteries
}

\author{
Ruijun Pan - Zhaohui Wang ( Rui Sun · Jonas Lindh • \\ Kristina Edström • Maria Strømme · Leif Nyholm
}

Received: 9 February 2017 / Accepted: 24 April 2017/Published online: 26 April 2017

(C) The Author(s) 2017. This article is an open access publication

\begin{abstract}
The pore structure of the separator is crucial to the performance of a lithium-battery as it affects the cell resistance. Herein, a straightforward approach to vary the pore structure of Cladophora cellulose (CC) separators is presented. It is demonstrated that the pore size and porosity of the $\mathrm{CC}$ separator can be increased merely by decreasing the thickness of the CC separator by using less $\mathrm{CC}$ in the manufacturing of the separator. As the pore size and porosity of the $\mathrm{CC}$ separator are increased, the mass transport through the separator is increased which decreases the electrolyte resistance in the pores of the separator. This enhances the battery performance, particularly at higher cycling rates, as is demonstrated for $\mathrm{LiFePO}_{4} / \mathrm{Li}$ half-cells. A specific capacity of around $100 \mathrm{mAh} \mathrm{g}^{-1}$ was hence obtained at a cycling rate of $2 \mathrm{C}$ with a $10 \mu \mathrm{m}$ thick CC separator while specific capacities of 40 and close to $0 \mathrm{mAh} \mathrm{g}^{-1}$ were obtained for separators with thicknesses of 20 and $40 \mu \mathrm{m}$, respectively. As the results also showed that a
\end{abstract}

R. Pan · Z. Wang $(\bowtie) \cdot$ K. Edström $\cdot$ L. Nyholm $(\bowtie)$ Department of Chemistry-Ångström Laboratory, Uppsala University, Box 538, 75121 Uppsala, Sweden

e-mail: zhaohui.wang@kemi.uu.se

L. Nyholm

e-mail: leif.nyholm@kemi.uu.se

R. Sun · J. Lindh · M. Strømme

Nanotechnology and Functional Materials, Department of Engineering Sciences, The Ångström Laboratory, Uppsala University, Box 534, 75121 Uppsala, Sweden higher ionic conductivity was obtained for the $10 \mu \mathrm{m}$ thick CC separator than for the 20 and $40 \mu \mathrm{m}$ thick CC separators, it is clear that the different pore structure of the separators was an important factor affecting the battery performance in addition to the separator thickness. The present straightforward, yet efficient, strategy for altering the pore structure hence holds significant promise for the manufacturing of separators with improved performance, as well as for fundamental studies of the influence of the properties of the separator on the performance of lithium-ion cells.

Keywords Cellulose - Separator - Thickness · Porous structure $\cdot$ Lithium-ion batteries

\section{Introduction}

Due to their predominant role in energy storage systems (Goodenough and Kim 2011; Goodenough and Park 2013; Sobkowiak et al. 2013; Tarascon and Armand 2001; Wang et al. 2015; Wei et al. 2013; Yang and Hou 2012), lithium-ion batteries (LIBs) have been extensively studied during the past decades. However, relatively little effort has so far been made to systematically study the influence of the properties of the separator, one of the indispensable components in LIBs (Arora and Zhang 2004; Ryou et al. 2011), on the battery performance. The function of a separator in 
a LIB is generally twofold; it should prevent physical contact between the anode and cathode materials, and ensure fast ionic transport between the electrodes (Arora and Zhang 2004; Lee et al. 2014; Yang and Hou 2012; Zhang 2007). In order to fulfil these two functions, the pore structure and thickness of the separator must be carefully controlled, as a good balance between ionic conductivity and mechanical strength must be maintained (Arora and Zhang 2004; Lee et al. 2014; Zhang 2007).

Contemporary LIB separators, which typically are made from polyolefin-based polymer materials, generally suffer from low thermal stabilities and electrolyte wettabilities (Chun et al. 2012; Prasanna et al. 2014; Ryou et al. 2011; Weng et al. 2015; Xu et al. 2014a, b; Zhang et al. 2013, 2014; Zhou et al. 2013) which has resulted in a search for alternative separator materials. One of the most studied and utilized alternative materials is cellulose, due to its abundance, thermal stability, hydrophilicity and low cost (Carlsson et al. 2014; Gustafsson et al. 2016; Mihranyan 2011; Pan et al. 2016; Wang et al. 2014; Xiao et al. 2014; Zhu et al. 2016; Zolin et al. 2015). It has been reported that cellulose/polysulfonamide composite separators exhibit good wettabilities and high thermal stabilities (Xu et al. 2014b) and that cellulose membranes produced by force spinning of cellulose acetate also exhibit good wettabilities, high porosities and high ionic conductivities (Weng et al. 2015). A bacterial cellulose based separator composed of a cross-linked three dimensional network exhibiting good performance in a battery has likewise been demonstrated (Jiang et al. 2015). Since cellulose often contains significant amounts of water it is, however, very important to choose a type of cellulose that contains as little water as possible (Lu et al. 2016). We have recently shown that separators made from Cladophora cellulose (CC) are particularly well-suited due to the low water content of this type of cellulose (Pan et al. 2016). It was demonstrated that a $36 \mu \mathrm{m}$ thick CC separator, exhibited a better performance than the Solupor ${ }^{\circledR}$ control separator, in terms of thermal stability, wettability and ionic conductivity (Pan et al. 2016). These results show that $\mathrm{CC}$ is a promising separator material that is worth further studies particularly as such separators most likely can be manufactured using upscalable paper-making processes.

In addition to the separator material, the pore structure and porosity of the material are clearly very important to the performance of the separator in a battery. To facilitate systematic studies of the influence of these properties on the performance of LIBs there is therefore a need for straightforward methods by which the pore structure and porosity of a specific material can be varied conveniently. The objective is to be able to tailor the pore structure in such a way that separators with good ion transport and sufficient mechanical properties readily can be manufactured. Previous results have shown that the pore structure of cellulose-based membranes can be tailored with different drying methods and by incorporating various additives (Carlsson et al. 2012; Chun et al. 2012; Gustafsson and Mihranyan 2016; Kim et al. 2013). We are, however, not aware of any studies on cellulose based LIB separators focused on the thickness dependence of the pore structure, i.e. the pore size distribution and porosity. The latter is, however, not surprising as it is reasonable to assume that the pore structure of a separator should be independent of the separator thickness. While this assumption may be true for some porous systems, e.g. polyolefin separators produced by stretching and anodic aluminum oxide membranes, it is not necessarily true for cellulose based separators manufactured using paper-making processes.

In the present work, we describe a straightforward paper-making filtration process by which CC separators with different thicknesses and pore structures can be manufactured merely by varying the amount of cellulose used. This approach allows CC separators with different thicknesses and pore structures to be manufactured without employing external pressure or different drying techniques. It is shown that thinner separators exhibit a less compact structure with larger pores and higher porosities and that this gives rise to LIBs with lower cell resistances. $\mathrm{A} \mathrm{LiFePO}_{4} / \mathrm{Li}$ battery containing a $10 \mu \mathrm{m}$ CC separator, exhibiting the largest pores and the highest porosity, is shown to feature a specific capacity of about $100 \mathrm{mAh} \mathrm{g}^{-1}$ at a rate of $2 \mathrm{C}$. Ionic conductivity data clearly show that the cell resistance for a thinner separator was significantly decreased as a result of its more open pore structure.

\section{Experimental section}

Materials

Cladophora cellulose powder (Batch NO. G3828117), produced from Cladophora green algae, was 
supplied by FMC Biopolymer USA whereas lithium iron phosphate $\left(\mathrm{LiFePO}_{4}\right)$, Super $\mathrm{P}$ (Erachem), polyvinylidene fluoride (PVdF, Kynar Flex Arzkema), nylon filter membranes ( $\phi 90 \mathrm{~mm}, 0.45 \mu \mathrm{m}$, Magna) and Li foil (thickness $125 \mu \mathrm{m}$, Cyprus Foote Minerals) were purchased from the indicated suppliers. The LP40 electrolyte [i.e. 1.0 M lithium hexafluorophosphate in ethylene carbonate/diethyl carbonate (1/1, $\mathrm{v} / \mathrm{v})$ ] was prepared in the lab using commercial chemicals. The other chemicals and materials used in the work (e.g. deionized water, aluminum foil and copper foil) were obtained from commercial manufacturers and all materials were used as received without any further purification.

\section{Preparation of CC separators}

The CC separators were manufactured based on the paper-making approach described in our previous publication (Pan et al. 2016). In the present work, a dispersion of $300 \mathrm{mg} \mathrm{CC}$ in $200 \mathrm{~mL}$ water was prepared by ultrasonication (VibraCell $750 \mathrm{~W}$, Sonics, USA) for $15 \mathrm{~min}$. Different volumes (i.e. 25, 50 and $100 \mathrm{~mL}$ ) of $\mathrm{CC}$ dispersion were used to prepare separators with different thicknesses. The wet separators were dried at $70{ }^{\circ} \mathrm{C}$ and atmospheric pressure for $12 \mathrm{~h}$ without applying external pressure (i.e. free drying). This approach differs from that used in our previous work where two aluminum plates were used to clamp the wet separator (i.e. constraint drying) during the drying (Pan et al. 2016). The notations CC25, CC-50 and CC-100 are used to denote separators prepared with 25,50 and $100 \mathrm{~mL} \mathrm{CC}$ dispersion, respectively. The thicknesses of the CC-25, CC-50 and CC-100 separators were found to be 10,20 and $40 \mu \mathrm{m}$, respectively, using a digital precision caliper (Mitutoyo Absolute, Japan).

\section{Characterization}

\section{Scanning electron microscopy (SEM)}

The surface and cross-sectional morphologies of the separators were examined using a field emission scanning electron microscope (Zeiss LEO1550, Germany). The samples were sputtered with a thin layer of gold/palladium for $30 \mathrm{~s}$ before being mounted onto aluminum stubs with double-sided conductive tape.

\section{Nitrogen sorption}

Nitrogen sorption analyses were conducted at $-194{ }^{\circ} \mathrm{C}$ employing a Micromeritics ASAP2020 surface area analyzer. The pore volume and pore size distributions were fitted and calculated according to the Barrett-Joyner-Halenda (BJH) model. Before the analyses, all samples were degassed at $100{ }^{\circ} \mathrm{C}$ under dynamic vacuum $\left(1 \times 10^{-3} \mathrm{~Pa}\right)$ for $6 \mathrm{~h}$.

\section{Electrochemical impedance spectroscopy (EIS)}

The ionic conductivities of the electrolyte soaked separators were determined using EIS measurements performed within the $1 \mathrm{~Hz}-100 \mathrm{kHz}$ frequency range using a VMP instrument (Biologic Multichannel potentiostat). In these measurements, the cells were composed of two $\phi 13 \mathrm{~mm}$ copper electrodes separated by the different separators which had been soaked with the same volume of LP40 electrolyte (i.e. $75 \mu \mathrm{L}$ ). This volume was found to be sufficient to fully soak even the thickest separator. The measurements were performed at the open circuit voltage employing an ac amplitude of $10 \mathrm{mV}$. In each case, the cell resistance $R_{s}$, obtained from the high frequency intercept in the Nyquist plot, was used to determine the ionic conductivity $(\sigma)$ of the LP40 soaked separator using $\sigma=L /\left(R_{s} \times A\right)$, where $\mathrm{L}$ denotes the thickness of the separator and A the area of the copper electrodes.

EIS measurements were also carried out on $\mathrm{LiFePO}_{4} / \mathrm{Li}$ cells containing different separators to compare their cell resistances. The latter measurements were performed for fresh-made cells between $200 \mathrm{mHz}$ and $200 \mathrm{kHz}$ at their open circuit potentials (around $3.2 \mathrm{~V}$ ) using an ac amplitude of $10 \mathrm{mV}$.

\section{Charge and discharge curves}

Galvanostatic (i.e. chronopotentiometric) experiments at different rates were carried out on an Arbin BT2043 cycling equipment. The cycled LIBs contained a $\mathrm{LiFePO}_{4}$ composite electrode (LFP/carbon black/ PVdF, 80/10/10, $13 \mathrm{~mm}$ disc with active mass loading of around $1 \mathrm{mg} \mathrm{cm}^{-2}$ ) and a lithium disc combined counter and reference electrode, LP40 electrolyte and one of the three studied CC separators (i.e. CC-25, CC50 or CC-100). An aluminum foil was used as the current collector for the cathode, while a copper 
current collector was used for the anode. The LFP composite electrode was prepared with a doctor blade method using slurry mixed in a high energy ball milling machine. The cells were first cycled at different rates, i.e. $0.1 \mathrm{C}, 0.2 \mathrm{C}, 0.5 \mathrm{C}, 1 \mathrm{C}$ and $2 \mathrm{C}$ (where $\mathrm{x} \mathrm{C}$ indicates that the cell can be fully charged/ discharged in $1 / \mathrm{x} \mathrm{h}$ ) for five cycles after which the cells were cycled at a rate of $0.5 \mathrm{C}$ for five cycles between 2.5 and $4.2 \mathrm{~V}$ versus $\mathrm{Li}^{+} / \mathrm{Li}$. To study the cycling stability of a battery containing the CC-25 separator, the cells were cycled on the Arbin cycler at a rate of $1 \mathrm{C}$ for 50 cycles.

\section{Results and discussion}

Previous studies (Gustafsson et al. 2016; Pan et al. 2016) have indicated that CC based separators manufactured using the present paper-making process exhibit a layered cross-sectional structure featuring layers composed of randomly intertwined CC fibers. This indicates that it should be possible to modify the pore structure of the CC separators by merely adjusting their thicknesses. When cellulose fibers with similar structures are randomly stacked, the pores in the obtained cellulose layer will be partly blocked or divided when new fibers are added. This means that the overall porosity and average pore size of the separator will decrease as its thickness increases, as is schematically shown in Fig. 1. The $10 \mu \mathrm{m}$ thick CC25 separator is therefore expected to feature larger pores and a higher porosity than the CC-50 and CC100 separators which were found to have thicknesses of 20 and $40 \mu \mathrm{m}$, respectively. This is in good agreement with the results presented in Fig. 2. The digital images of the cellulose CC-25, CC-50 and CC100 separators shown in Fig. 2 (top row) thus demonstrate that the transparency of the separators decreased with increasing thickness. The SEM images also show that the CC-25 separator featured larger pores and a less compact structure than the CC-50 and CC-100 separators, despite the fact that the fiber morphology and overall structure (entangled CC fibers with a thickness of around $30 \mathrm{~nm}$ ) were the same in all three cases. Since all three separators were manufactured from the same raw material using the same procedure, it is hence clear that their microstructures differed merely as a result of their different thicknesses (see the SEM images in Fig. 2a-c), in accordance with the hypothesis described in Fig. 1.

The pore structures of the CC-25, CC-50 and CC100 separators were further examined using nitrogen adsorption experiments in which the pore size distributions were analyzed with the BJH method (see Fig. 3). These results were in good agreement with the SEM results as the peak pore sizes were 21,13 and $12 \mathrm{~nm}$, for the CC-25, CC-50 and CC-100 separators, respectively (see Table 1 ). It can also be noted that the CC-50 separator featured more pores with a size larger than $15 \mathrm{~nm}$ than the CC-100 sample, although both separators showed similar peak pore sizes. The latter finding indicates that the CC-50 separator had a more porous structure than the $\mathrm{CC}-100$ separator due to its lower thickness. Furthermore, the specific pore volume of the CC-25 membrane was much larger than those of the other two separators, as indicated by the areas under the pore size distribution curves in Fig. 3a. The porosities calculated based on the detected pores using the nitrogen adsorption technique and a true density of $1.64 \mathrm{~g} \mathrm{~cm}^{-3}$ for CC (Ek et al. 1998; Mihranyan 2011) were 44, 37 and 33\%, for the CC-25, CC-50 and CC-100 separators. The estimation of the porosity according to this procedure is expected to give reliable results since the $\mathrm{CC}$ separators mainly
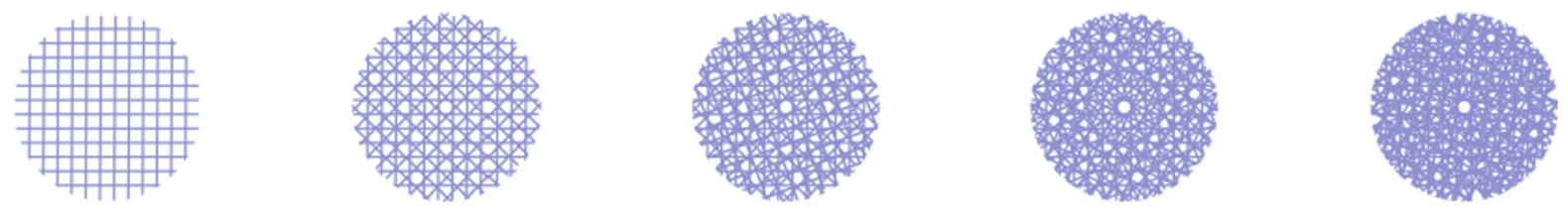

Pore size

Fig. 1 Schematic illustration describing the pore structure evolution during the separator manufacturing process. It can be seen that thin separators exhibit larger pores and a higher porosity than thicker separators composed of more cellulose fibers 

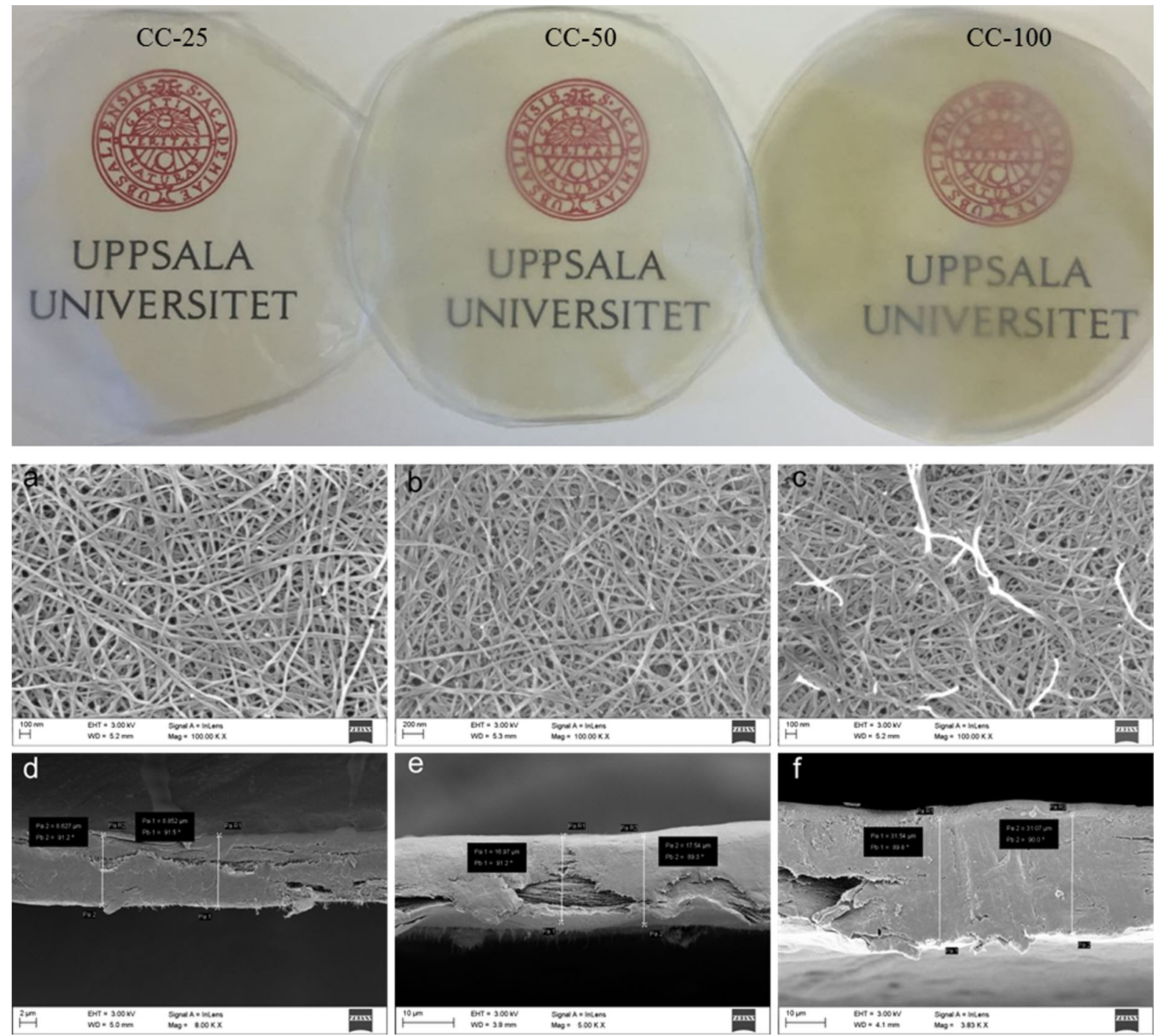

Fig. 2 Top row: Digital images of the CC-25, CC-50 and CC100 separators positioned on top of the Uppsala University logo to demonstrate their different transparencies; Surface (a-c) and

contain micropores and mesopores as demonstrated in our previous work (Pan et al. 2016). This clearly shows that the pore size distribution and the porosity (i.e. the pore structure) of the CC separators can indeed be controlled merely by altering the thickness of the separators. The smaller porosity value for the CC-100 separator, i.e. $36 \%$, compared to the value of $46 \%$ reported in our previous work for a separator containing a similar amount of CC $(150 \mathrm{mg})$, can be explained by the different drying methods used in these two studies. It has been shown that CC membranes shrink somewhat during their drying to cross section (d-f) SEM images of the CC-25 (a, d), CC-50 (b, e), CC-100 (c, f) separators

yield a more compact structure and different drying methods can hence lead to different porosities and separator thicknesses (Gustafsson and Mihranyan 2016).

The relatively larger pores and higher porosity for the CC-25 separator should facilitate the incorporation of the electrolyte into the separator and may also improve the battery performance as a result of the higher ionic conductivity $(\sigma)$ of the electrolyte soaked separator. The ionic conductivities, calculated from EIS measurement using symmetric cells containing two copper electrodes (see Fig. $3 b$ ) were $0.82,0.79$ 
Fig. 3 Pore size distribution (a), high frequency part of the Nyquist plots used in the ionic conductivity determinations (b)
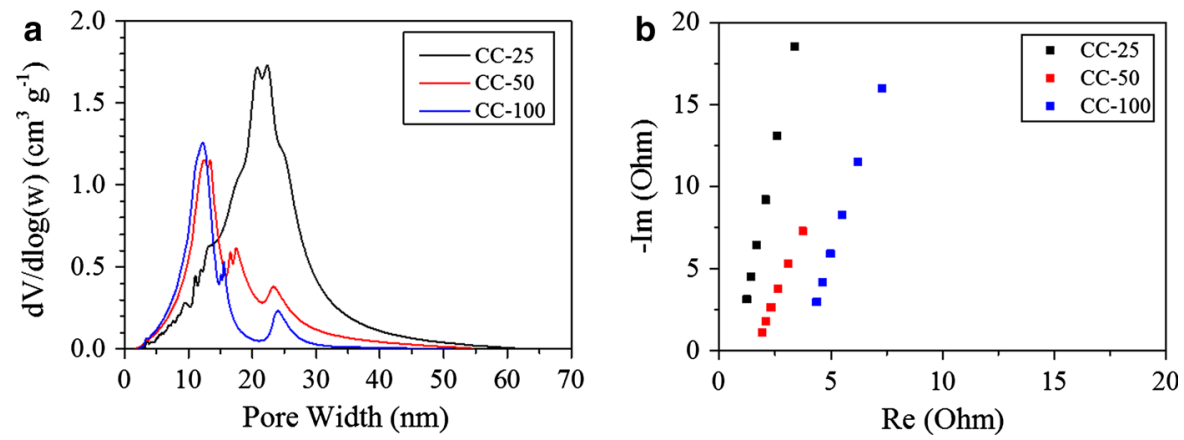

Table 1 Thickness, peak pore size, porosity and ionic conductivity values for the studied CC separators

\begin{tabular}{lllll}
\hline & Thickness $(\mu \mathrm{m})$ & Pore size $(\mathrm{nm})$ & Porosity $(\%)$ & $\sigma\left(\mathrm{mS} \mathrm{cm}^{-1}\right)$ \\
\hline CC-25 & 10 & 21 & 44 & 0.82 \\
CC-50 & 20 & 13 & 37 & 0.79 \\
CC-100 & 40 & 12 & 33 & 0.69 \\
\hline
\end{tabular}

and $0.69 \mathrm{mS} \mathrm{cm} \mathrm{cm}^{-1}$ for the CC-25, CC-50 and CC-100 separators, respectively. These results demonstrate that the CC-25 separator should give rise to a smaller electrolyte resistance not only due to its smaller thickness but also due to its more open pore structure.

The peak pore size, porosity and ionic conductivity data for the different separators presented in Table 1 clearly show that the properties of the CC-25, CC-50 and CC-100 separators are in good agreement with the trends expected based on the schematic model in Fig. 1. The behavior seen here is therefore different from that typically expected as it is normally reasonable to assume that the ionic conductivity, porosity and pore size are independent of the separator thickness. However, our experimental show that an increased separator thickness (from 10 to $40 \mu \mathrm{m}$ ) gave rise to a decrease in the porosity (from 44 to $33 \%$ ), peak pore size (from 21 to $12 \mathrm{~nm}$ ) and ionic conductivity (from 0.82 to $0.69 \mathrm{mS} \mathrm{cm}^{-1}$ ). It can consequently be concluded that the pore structure of $\mathrm{CC}$ separators can be modified merely by changing the separator thickness. This provides new possibilities with respect to systematic investigations of the influence of the properties of the separator on the performances of e.g. LIBs.

To assess the influence of the separator thickness on the LIB performance, galvanostatic cycling tests were carried out with $\mathrm{LiFePO}_{4} / \mathrm{Li}$ batteries (with similar active mass loadings of around $1 \mathrm{mg} \mathrm{cm}^{-2}$ ) at several rates (i.e. $0.1 \mathrm{C}, 0.2 \mathrm{C}, 0.5 \mathrm{C}, 1 \mathrm{C}, 2 \mathrm{C}$ and finally 0.5 $\mathrm{C})$, as is shown in Fig. 4. The battery with the thinnest separator, i.e. CC-25, exhibited the highest specific capacity and the smallest overpotentials (i.e. the smallest difference between the charge and discharge plateaus, see Fig. $4 \mathrm{a}-\mathrm{c}$ ) at all rates. It can be seen that the differences between the cells containing the different separators were more pronounced at high rates. Note that the $\mathrm{CC}-100$ based battery could not be used at a rate of $2 \mathrm{C}$, while batteries with the CC-25 and CC-50 separators still delivered capacities of about 100 and $40 \mathrm{mAh} \mathrm{g}^{-1}$, respectively (see Fig. 4ac, e). The results in Fig. 4 can be explained based on the different cell resistances of the different cells. As the only difference between the cells was the employed separator it is immediately evident that the CC-25 based cell had the lowest cell resistance. This conclusion is also supported by the EIS data presented in Fig. 4d (see e.g. the different high frequency intercepts in the inset). As the electrolyte resistance should be proportional to the separator thickness, the good cycling performance of the CC- 25 based cell can mainly be explained by the fact that this separator was thinner than the others. However, the higher conductivity of the CC-25 separator discussed above should also have contributed to the lower cell resistance. To minimize the cell resistance and hence to optimize the 

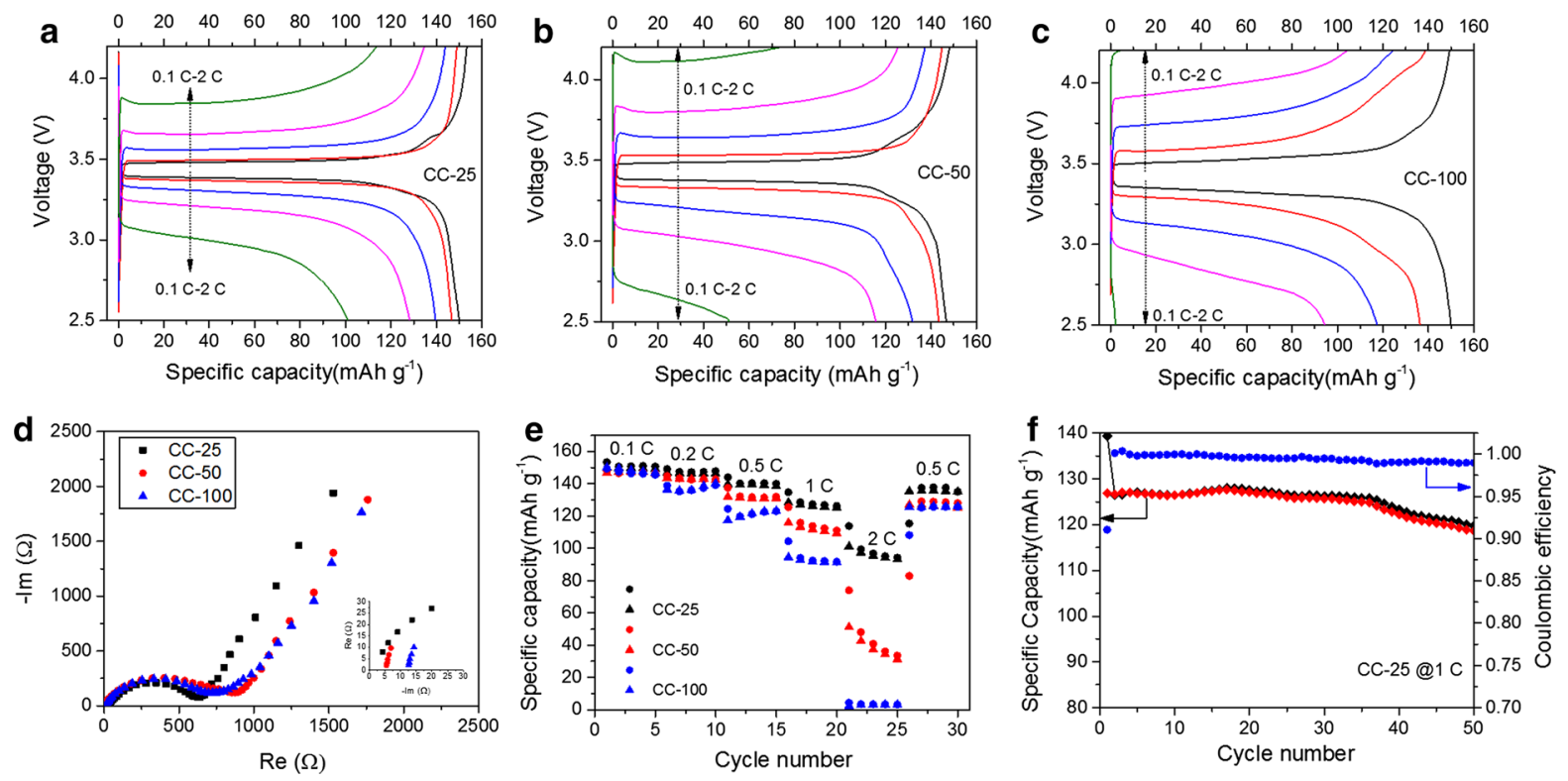

Fig. 4 Charge and discharge curves recorded at different cycling rates for the CC-25, CC-50 and CC-100 based cells (a-c), Nyquist plots recorded prior to the galvanostatic cycling (d), specific capacity versus cycle number plots obtained at rates

high rate cycling performance the separator should therefore be as thin as possible and have an ionic conductivity as high as possible while still eliminating the risk of short-circuits between the electrodes. As no problems with short-circuits were encountered in the present study, it is clear that $10 \mu \mathrm{m}$ thin CC LIB separators can be readily made with the paper-making process described herein. It is also clear that the ionic conductivity of the $\mathrm{CC}$ separator increases with decreasing thickness as a result of the process described in Fig. 1. It should also be mentioned that access to thin separators facilitate the design of LIBs with higher energy densities.

To investigate the cycling stability a CC- 25 based $\mathrm{LiFePO}_{4} / \mathrm{Li}$ battery was also subjected to galvanostatic cycling at a rate of $1 \mathrm{C}$ for 50 cycles. The cell showed stable cycling, as is seen in Fig. $4 \mathrm{f}$, and the battery exhibited an initially capacity of more than $125 \mathrm{mAh} \mathrm{g}^{-1}$ and a capacity retention of $93 \%$ after 50 cycles. It should also be noted that this capacity retention deviated from that expected based on the coulombic efficiency of $99 \%$ which should give rise to a capacity retention of merely about $60 \%$ (as $0.99^{50}=0.60$ ). The fact that the experimental capacity retention value was found to be $93 \%$ found after 50 cycles thus indicates that the coulombic efficiency in between $0.1 \mathrm{C}$ and $2 \mathrm{C}(\mathbf{e})$, and the specific capacity as a function of the cycle number for a CC-25 containing cell cycled at a rate of $1 \mathrm{C}(\mathbf{f})$

fact was as high as about $99.9 \%$ (as $0.999^{50}=0.93$ ). This illustrates the problems associated with the conventional calculations of coulombic efficiencies which often contain significant uncertainties and also are affected by irreversible side-reactions (e.g. oxygen reduction) even though these do not affect the charge and discharge reactions. More importantly, the results show that the approach used in the present work is effective in controlling the pore structure of the CC separators and an improved cycling performance could be obtained for $\mathrm{LiFePO}_{4} / \mathrm{Li}$ batteries when using the $10 \mu \mathrm{m}$ thick CC-25 separator as a result of a decreased electrolyte resistance. While the latter mainly stemmed from the small thickness of the separator, there was also a contribution from the open pore structure of this separator. It can thus be concluded that improved LIB cycling performances can be obtained with the present $10 \mu \mathrm{m}$ thick CC separators.

\section{Conclusions}

A surprisingly facile paper-making approach has been described for the manufacturing of stratified Cladophora cellulose (CC) separators with different 
thicknesses and pore structures. The pore size distribution and porosity of the separators can be controlled merely by varying the amount of CC used in the manufacturing process as an increased thickness gives rise to a decreased porosity and peak pore size in the paper-making process. The method, which allows the manufacturing of $\mathrm{CC}$ separators with thicknesses down to $10 \mu \mathrm{m}$, therefore facilitates the manufacturing of separators based on the same material but with different pore structures and hence ionic conductivities. This provides new possibilities for systematic studies of the influence of the properties of the separator on the performance of e.g. lithium-ion batteries. It has been shown that a decrease in the CC separator thickness from 40 to $10 \mu \mathrm{m}$ results in an increase in the peak pore size from 12 to $21 \mathrm{~nm}$ as well as an increase in the porosity from 33 to $44 \%$, resulting in an increase in the ionic conductivity of the electrolyte soaked separators from 0.69 to 0.82 $\mathrm{mS} \mathrm{cm}{ }^{-1}$. A $\mathrm{LiFePO}_{4} / \mathrm{Li}$ battery equipped with a $10 \mu \mathrm{m}$ thick CC separator was found to exhibit a specific capacity of about $100 \mathrm{mAh} \mathrm{g}^{-1}$ at a cycling rate of $2 \mathrm{C}$ whereas the corresponding capacity for a cell containing a $20 \mu \mathrm{m}$ thick separator was limited to about $40 \mathrm{mAh} \mathrm{g}^{-1}$. The present experimental approach and the underlying pore structure manipulation technique are also expected to facilitate the development and understanding of the performance of other porous membrane systems used in batteries and other devices.

Acknowledgments The authors thank The Swedish Foundation for Strategic Research (Grant RMA-110012), The Swedish Energy Agency (project SwedGrids), Batterifonden (Project TriLi), StandUp for Energy for financial support. Dr. Ocean Cheung is acknowledged for help with the nitrogen sorption measurements.

Open Access This article is distributed under the terms of the Creative Commons Attribution 4.0 International License (http:// creativecommons.org/licenses/by/4.0/), which permits unrestricted use, distribution, and reproduction in any medium, provided you give appropriate credit to the original author(s) and the source, provide a link to the Creative Commons license, and indicate if changes were made.

\section{References}

Arora P, Zhang ZJ (2004) Battery Separators. Chem Rev 104:4419-4462. doi:10.1021/cr020738u
Carlsson DO, Nyström G, Zhou Q, Berglund LA, Nyholm L, Strømme M (2012) Electroactive nanofibrillated cellulose aerogel composites with tunable structural and electrochemical properties. J Mater Chem 22:19014. doi:10.1039/ c2jm33975g

Carlsson DO, Mihranyan A, Strømme M, Nyholm L (2014) Tailoring porosities and electrochemical properties of composites composed of microfibrillated cellulose and polypyrrole. RSC Adv 4:8489. doi:10.1039/c3ra47588c

Chun S-J, Choi E-S, Lee E-H, Kim JH, Lee S-Y, Lee S-Y (2012) Eco-friendly cellulose nanofiber paper-derived separator membranes featuring tunable nanoporous network channels for lithium-ion batteries. J Mater Chem 22:16618. doi: $10.1039 / \mathrm{c} 2 \mathrm{jm} 32415 \mathrm{f}$

Ek R, Gustafsson C, Nutt A, Iversen T, Nyström C (1998) Cellulose powder from Cladophora sp. algae. J Mol Recognit 11:263-265

Goodenough JB, Kim Y (2011) Challenges for rechargeable batteries. J Power Sources 196:6688-6694. doi:10.1016/j. jpowsour.2010.11.074

Goodenough JB, Park KS (2013) The li-ion rechargeable battery: a perspective. J Am Chem Soc 135:1167-1176. doi:10.1021/ja3091438

Gustafsson S, Mihranyan A (2016) Strategies for tailoring the pore-size distribution of virus retention filter papers. ACS Appl Mater Interfaces 8:13759-13767. doi:10.1021/ acsami.6b03093

Gustafsson S, Lordat P, Hanrieder T, Asper M, Schaefer O, Mihranyan A (2016) Mille-feuille paper: a novel type of filter architecture for advanced virus separation applications. Mater Horiz 3:320-327. doi:10.1039/c6mh00090h

Jiang F, Yin L, Yu Q, Zhong C, Zhang J (2015) Bacterial cellulose nanofibrous membrane as thermal stable separator for lithium-ion batteries. J Power Sources 279:21-27. doi:10.1016/j.jpowsour.2014.12.090

Kim J-H, Kim J-H, Choi E-S et al (2013) Colloidal silica nanoparticle-assisted structural control of cellulose nanofiber paper separators for lithium-ion batteries. J Power Sources 242:533-540. doi:10.1016/j.jpowsour.2013.05. 142

Lee H, Yanilmaz M, Toprakci O, Fu K, Zhang X (2014) A review of recent developments in membrane separators for rechargeable lithium-ion batteries. Energy Environ Sci 7:3857-3886. doi:10.1039/C4EE01432D

Lu H, Behm M, Leijonmarck S, Lindbergh G, Cornell A (2016) Flexible paper electrodes for li-ion batteries using low amount of TEMPO-oxidized cellulose nanofibrils as binder. ACS Appl Mater Interfaces 8:18097-18106. doi:10. 1021/acsami.6b05016

Mihranyan A (2011) Cellulose from cladophorales green algae: from environmental problem to high-tech composite materials. J Appl Polym Sci 119:2449-2460. doi:10.1002/ app.32959

Pan R, Cheung O, Wang Z et al (2016) Mesoporous Cladophora cellulose separators for lithium-ion batteries. J Power Sources 321:185-192. doi:10.1016/j.jpowsour.2016.04. 115

Prasanna K, Kim C-S, Lee CW (2014) Effect of $\mathrm{SiO}_{2}$ coating on polyethylene separator with different stretching ratios for application in lithium ion batteries. Mater Chem Phys 146:545-550. doi:10.1016/j.matchemphys.2014.04.014 
Ryou MH, Lee YM, Park JK, Choi JW (2011) Mussel-inspired polydopamine-treated polyethylene separators for highpower li-ion batteries. Adv Mater 23:3066-3070. doi:10. 1002/adma.201100303

Sobkowiak A, Roberts MR, Younesi R et al (2013) Understanding and controlling the surface chemistry of LiFeSO4F for an enhanced cathode functionality. Chem Mater 25:3020-3029. doi:10.1021/cm401063s

Tarascon JM, Armand M (2001) Issues and challenges facing rechargeable lithium batteries. Nature 414:359-367. doi: $10.1038 / 35104644$

Wang Z, Tammela P, Zhang P, Huo J, Ericson F, Strømme M, Nyholm L (2014) Freestanding nanocellulose-composite fibre reinforced 3D polypyrrole electrodes for energy storage applications. Nanoscale 6:13068-13075. doi:10. 1039/c4nr04642k

Wang Z, Xu C, Tammela P et al (2015) Flexible freestanding Cladophora nanocellulose paper based $\mathrm{Si}$ anodes for lithium-ion batteries. J Mater Chem A 3:14109-14115. doi:10.1039/c5ta02136g

Wei W, Oltean G, Tai C-W, Edström K, Björefors F, Nyholm L (2013) High energy and power density $\mathrm{TiO}_{2}$ nanotube electrodes for 3D Li-ion microbatteries. J Mater Chem A 1:8160. doi:10.1039/c3ta11273j

Weng B, Xu F, Alcoutlabi M, Mao Y, Lozano K (2015) Fibrous cellulose membrane mass produced via forcespinning ${ }^{\circledR}$ for lithium-ion battery separators. Cellulose 22:1311-1320. doi:10.1007/s10570-015-0564-8

Xiao S, Wang F, Yang Y, Chang Z, Wu Y (2014) An environmentally friendly and economic membrane based on cellulose as a gel polymer electrolyte for lithium ion batteries. RSC Adv 4:76. doi:10.1039/c3ra46115g

Xu Q, Kong Q, Liu Z et al (2014a) Polydopamine-coated cellulose microfibrillated membrane as high performance lithium-ion battery separator. RSC Adv 4:7845. doi:10. 1039/c3ra45879b

Xu Q, Kong QS, Liu ZH et al (2014b) Cellulose/polysulfonamide composite membrane as a high performance lithium-ion battery separator. ACS Sustain Chem Eng 2:194-199. doi:10.1021/sc400370h

Yang M, Hou J (2012) Membranes in lithium ion batteries. Membranes 2:367-383. doi:10.3390/membranes2030367

Zhang SS (2007) A review on the separators of liquid electrolyte Li-ion batteries. J Power Sources 164:351-364. doi:10. 1016/j.jpowsour.2006.10.065

Zhang J, Yue L, Kong Q et al (2013) A heat-resistant silica nanoparticle enhanced polysulfonamide nonwoven separator for high-performance lithium ion battery. J Electrochem Soc 160:A769-A774. doi:10.1149/2.043306jes

Zhang J, Yue L, Kong Q et al (2014) Sustainable, heat-resistant and flame-retardant cellulose-based composite separator for high-performance lithium ion battery. Sci Rep 4:3935. doi:10.1038/srep03935

Zhou X, Yue L, Zhang J, Kong Q, Liu Z, Yao J, Cui G (2013) A core-shell structured polysulfonamide-based composite nonwoven towards high power lithium ion battery separator. J Electrochem Soc 160:A1341-A1347. doi:10.1149/ 2.003309jes

Zhu H, Luo W, Ciesielski PN et al (2016) Wood-derived materials for green electronics, biological devices, and energy applications. Chem Rev 116:9305-9374. doi:10. 1021/acs.chemrev.6b00225

Zolin L, Destro M, Chaussy D, Penazzi N, Gerbaldi C, Beneventi D (2015) Aqueous processing of paper separators by filtration dewatering: towards Li-ion paper batteries. J Mater Chem A 3:14894-14901. doi:10.1039/c5ta03716f 